\title{
Photoleukocoria with smartphone photographs
}

This article was published in the following Dove Press journal: International Medical Case Reports Journal

\section{Víctor Manuel \\ Asensio-Sánchez \\ Lucía Díaz-Cabanas \\ Alba Martín-Prieto \\ Ophthalmology Department, Clinical University Hospital of Valladolid, \\ Valladolid, Spain}

Correspondence: Víctor Manuel Asensio-Sánchez

Ophthalmology Department, Clinical University Hospital of Valladolid, Av. Ramón y Cajal, S/N. 47005,

Valladolid, Spain

Tel +34983 377982

Email vmasensio@yahoo.es

\begin{abstract}
A 3-year-old boy was referred with suspected leukocoria in the right eye, detected in all smartphone photographs taken by his parents. His medical and family history was unremarkable. The visual acuity was 20/20 in both eyes. Eye examination revealed full motility and normal pupils. The ocular fundi and ultrasonography appeared normal. The child was looking to the left side in his photographs, away from the camera, and illuminating the nasal retina. In this circumstance, the optic nerve head acts as a diffuse reflector, reflecting the light out of the eye through the pupil. In the case of normal clinical findings in a child presenting leukocoria in smartphone photographs (photoleukocoria), the ophthalmologist should suspect the possibility of the described phenomenon avoiding other studies.
\end{abstract}

Keywords: leukocoria, eye manifestations, white pupil, normal examination, reflex, false negative reflex

\section{Introduction}

Leukocoria is the medical term for the white eye reflex common in several childhood eye diseases affecting any of the structures that form the visual axis, including the cornea, the lens, the vitreous, and the retina. ${ }^{1}$ The majority of these conditions are significant for visual impairment and other conditions, as retinoblastoma can be lifethreatening. ${ }^{2-5}$ Leukocoria, which requires urgent evaluation by an ophthalmologist, represents a great challenge in ophthalmology. ${ }^{4,6}$ Leukocoria can be detectable through simple flash photography ${ }^{7,8}$ and the popularization of smartphone cameras enables parents to look for early diagnosis, seeing a white eye instead of the typical red eye in photographs, a phenomenon known as photoleukocoria. ${ }^{9}$ Any process that prevents the flash light of a camera from reaching the retina will produce photoleukosis. ${ }^{4} \mathrm{We}$ report a case of a 3-year-old boy who presented with leukocoria in the right eye, noted in all his smartphone photographs, but with normal ocular examination.

\section{Clinical case}

A 3-year-old male infant with his alarmed parents were referred to our emergency department for a 1-month history of leukocoria in the right eye, which was detected in all smartphone photographs taken at different times (Figure 1). Birth history: 36-week gestation and normal vaginal delivery. His mother denied smoking, drug use, and alcohol intake during pregnancy. His parents had no specific concerns on history. On examination, his visual acuity was $20 / 20$ in both eyes without glasses. No significant finding was observed on anterior segment examination. Ocular alignment and motility 


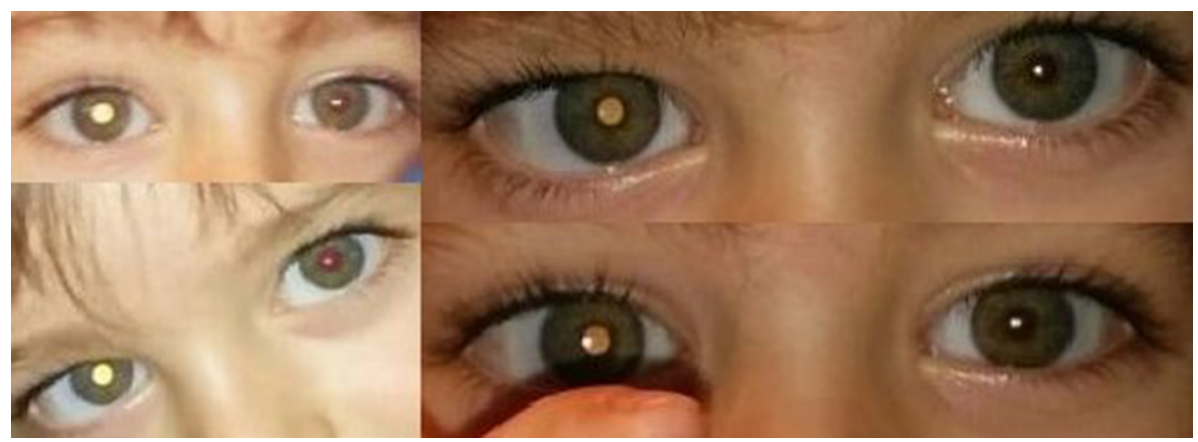

Figure I Four different smartphone photographs. In all pictures the child is not fixing directly on the camera, which resulted in a white pupillary reflex. Leukocoria is due to reflection off the optic nerve head.

were normal. No nystagmus was observed. He had no afferent pupillary defect. Dilated fundus examination appeared normal with a clear vitreous and no masses in the retina. The macula showed a normal reflex, and the disc margins were distinct (Figure 2). B-scan ultrasonography on the patient did not show any underlying retinal pathology (Figure 3). The child was scheduled for a 6-month review and, at the follow-up visit, his vision was 20/20 in both eyes with clear ocular media and normal fundi.

\section{Discussion}

Leukocoria, from the greek "leucos" (white) and "korê" (pupil), means "white pupil" and describes the clinical finding of a white pupillary reflex., ${ }^{3,410,11}$ Several eye conditions can cause white pupil as a first sign, such as congenital cataract, retinoblastoma, retinopathy of prematurity, nematode endophthalmitis, persistent hyperplastic primary vitreous, Coats' disease, ocular toxocariasis, retinal hamartomas, severe refractive error, organized vitreous hemorrhage, ocular albinism, myelinated fibers, and the presenting sign of abusive head trauma. ${ }^{2-4,11} \mathrm{~A}$ white pupil is often noticed by parents or relatives on flash photography, this is the first reason for consultation, as in our patient, where a consistent leukocoria appeared in the right eye, similar to a cat's eye reflection. The presence of an apparent leukocoria in a normal eye in a photograph taken from a temporal side has been reported previously. ${ }^{12,13}$ This finding can occur repeatedly in the same patient, but always in one eye only. In our patient, the apparent leukocoria was always evident in the right eye. This phenomenon has been reported when photographs are taken with an amateur camera with flash coaxially to the camera lens in eyes with undilated pupils and when the child's eye is turned toward the nose. ${ }^{12,13}$ The retina, at the point of the optic disc, contains no rod or cone cells, so it cannot process light. When a camera flash hits the optic disc directly, light is reflected back, causing the pupil to appear white, even though the eye is healthy. This

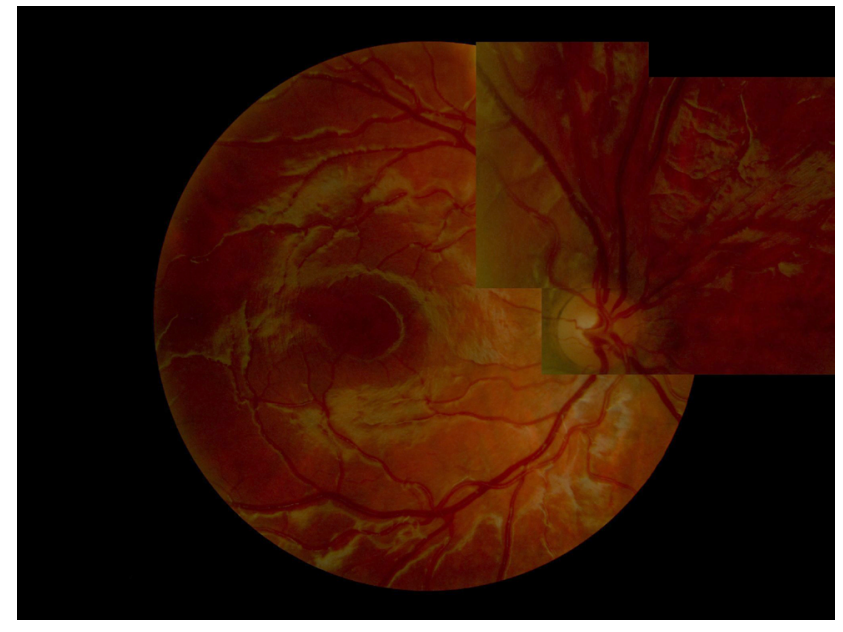

Figure 2 Color fundus photograph composition of this patient's right eye. Optic nerve, vessels, and macula are normal. Notice the retinal nerve fiber layer, especially detectable around the fovea and vasculature, a normal finding in children.

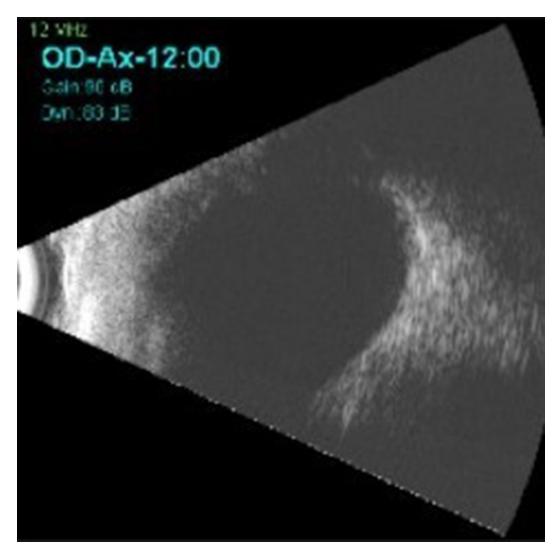

Figure 3 B-scan ultrasonography confirming normal posterior pole of the right eye.

reflection most often occurs when the child's eye is turned about $15^{\circ}$ toward the nose and the flash light hits the optic disc directly. ${ }^{12,13}$ In our child, each picture (shown in Figure 1) was looking in the opposite direction: right leukocoria was evident in left gaze. Each photograph was an outdoor photo taken with a smartphone camera at different times and at different 
distances of the camera and was fixating off axis. Marshall and Gole $^{12}$ reported an observational case series of three children who presented with unilateral leukocoria seen in flash photographs and normal ocular exploration. The photographs were all found to be approximately $15^{\circ}$ off axis, with the leukocoria seen in the eyes where the flash illuminated the nasal retina. This is known as photoleukocoria and it is normal. Batra et al ${ }^{13}$ described seven children referred due to unilateral leukocoria detected in amateur photographs. Each child had a normal ocular examination. In keeping with the findings reported in our patient, leukocoria was unilateral and in the eye in which the nasal retina was illuminated. They consider that leukocoria in normal eyes detected by flash photography only occurs in off-axis fixation. ${ }^{13}$ Different camera angles reflect light differently and can sometimes show a false leukocoria, especially in children looking directly at the camera. For reasons unknown, photos taken with smartphones can also create sporadic false positives in the same eye. As smartphones frequently capture false leukocoria, they are not the best tool for red reflex screening photos. However, false leukocoria can only be confirmed by an ophthalmologist through a red reflex eye exam. All children with newly discovered leukocoria should be referred to an ophthalmologist to exclude life- or sight-threatening diseases.

\section{Acknowledgment}

The authors confirm that written informed consent has been provided by the patient's parents to have the case details and any accompanying images published.

\section{Disclosure}

The authors report no conflicts of interest in this work.

\section{References}

1. Damasco VC, Dire DJ. A child with leukocoria. Pediatr Emerg Care. 2011;27(12):1170-1174.

2. Tuli SY, Giordano BP, Kelly M, Fillipps D, Tuli SS. Newborn with an absent red reflex. J Pediatr Health Care. 2013;27(1):51-55.

3. Haider S, Qureshi W, Ali A. Leukocoria in children. J Pediatr Ophthalmol Strabismus. 2008;45(3):179-180.

4. McLaughlin C, Levin AV. The red reflex. Pediatr Emerg Care. 2006;22(2):137-140.

5. Patel N, Salchow DJ, Materin M. Differentials and approach to leukocoria. Conn Med. 2013;77(3):133-140.

6. Abramson DH, Frank CM, Susman M, Whalen MP, Dunkel IJ, Boyd NW III. Presenting signs of retinoblastoma. J Pediatr. 1998;132(3 Pt 1):505-508.

7. Morgan KS, Kennemer JC. Off-axis photorefractive eye screening in children. J Cataract Refract Surg. 1997;23:423-428.

8. Tong PY1, Bassin RE, Enke-Miyazaki E, et al. Screening for amblyopia in preverbal children with photoscreening photographs: sensitivity and specificity of the MTI photoscreener. Ophthalmology. 2000;107(9):1623-1629.

9. Recchia FM. Retinoblastoma. In: Ho AC, Brown GC, Arch McNamara J, Recchia FM, Regillo CD, Vander JF, editors. Retina. Color Atlas \& Synopsis of Clinical Ophthalmology. New York, NY: McGraw-Hill; 2003:180-182.

10. Simon JW, Kaw P. Commonly missed diagnoses in the childhood eye examination. Am Fam Physician. 2001;64(4):623-628.

11. Patel N, Salchow DJ, Materin M. Differentials and approach to leukocoria. Conn Med. 2013;77(3):133-140.

12. Marshall J, Gole GA. Unilateral leukocoria in off axis flash photographs of normal eyes. Am J Ophthalmol. 2003;135(5):709-711.

13. Batra R, Rowe F, Rowlands A, Noonan C. Unilateral leucocoria in clinically normal eyes. Br J Ophthalmol. 2009;93(4):556-557.
International Medical Case Reports Journal

\section{Publish your work in this journal}

The International Medical Case Reports Journal is an international, peer-reviewed open-access journal publishing original case reports from all medical specialties. Previously unpublished medical postscience. Submissions should not normally exceed 2,000 words or ers are also accepted relating to any area of clinical or preclinical

Submit your manuscript here: https://www.dovepress.com/international-medical-case-reports-journal-journal

4 published pages including figures, diagrams and references. The manuscript management system is completely online and includes a very quick and fair peer-review system, which is all easy to use. Visit http://www.dovepress.com/testimonials.php to read real quotes from published authors. 